\title{
CUSTEIO-ALVO EM SERVIÇOS HOSPITALARES UM ESTUDO SOB O ENFOQUE DA GESTÃO ESTRATÉGICA DE CUSTOS
}

\author{
TARGET COSTING IN HOSPITAL SERVICES: A STUDY \\ FROM A STRATEGIC COST MANAGEMENT FOCUS
}

\author{
REINALDO RODRIGUES CAMACHO \\ Professor Mestre do Departamento de Ciências Contábeis \\ da Universidade Estadual de Maringá \\ E-mail: rcamacho@usp.br
}

\author{
WELINGTON ROCHA \\ Professor Doutor do Departamento de Contabilidade e Atuária \\ da Faculdade de Economia, Administração e Contabilidade \\ da Universidạde de São Paulo - Campus Capital \\ E-mail:cmslab@usp.br
}

\section{RESUMO}

Neste trabalho, os autores verificaram a viabilidade de aplicação do Custeio-alvo em serviços hospitalares. Como produto-teste da pesquisa, elegeu-se a cesariana realizada por meio de planos de saúde, com internação em apartamentos Standard. Para alcançar os objetivos da pesquisa aplicou-se o método de estudo de caso único e utilizaram-se diversas fontes de dados, tais como: levantamento bibliográfico, aplicação de questionário, realização de entrevistas, observação direta dos processos e atividades e análise e interpretação de relatórios contábeis, financeiros e administrativos da entidade hospitalar objeto do estudo. O questionário foi aplicado a um grupo de cinqüenta mulheres, com o objetivo de verificar sua percepção em relação ao grau de importância de cada um dos principais atributos do produto-teste. As entrevistas, realizadas com os principais gestores da entidade, tiveram o objetivo de yerificar como são estabelecidos preços e margens. A análise documental, realizada em planilhas de custos, balancetes e demais relatórios contábeis, financeiros e administrativos, contribuiu para conhecer os procedimentos adotados pela instituição para mensurar e controlar seus custos e receitas. Os resultados mostraram que o processo de Custeio-alvo pode ser aplicado, com sucesso, a entidades hospitalares.

Palavras-chave: Custo-alvo. Serviços hospitalares. Cesariana.

\section{ABSTRACT}

In this paper, the authors verified the practicability of applying Target Costing to hospital services. The caesarian section was selected as the research product for testing, carried out in patients hospitalized in a standard room, using a health insurance. To achieve the research aims, the single case study method was used, and also several data sources, such as: bibliographic survey, application of questionnaire, interviews, direct observation of processes and activities, and analysis and interpretation of accounting, financial and administrative reports from the hospital entity chosen for this study. The questionnaire was applied to a group of 50 (fifty) women in order to verify their perception concerning the degree of importance they attach to each main characteristic of the test product. The interviews, performed with the main entity directors, aimed to verify how the prices and margins are established. The documental analysis, carried out in cost spreadsheets, balance sheets and other accounting, financial and administrative reports, contributed to get to know the procedures adopted by the entity to measure and control its costs and revenues. The results demonstrated that the Target Costing process can successfully be applied to hospital entities.

Keywords: Target cost. Hospital services. Caesarian. 


\section{INTRODUÇÃO}

A omissão, aliada à incompetência dos governos brasileiros, na área de saúde, vem de longa data. Embora haja algumas ilhas de excelência, a situação predominante da saúde pública no país é ruim; com freqüência os meios de comunicação mostram pessoas sofrendo nas filas dos hospitais públicos, esperando atendimento. Diante disso, aqueles que têm condições financeiras optam por associar-se a um plano de saúde que lhes dê cobertura pois, do contrário, dependerão da assistência precária do governo. Segundo a Agência Nacional de Saúde (2004), mais de 37 milhões de pessoas encontram-se amparadas por um plano e existem mais de duas mil empresas operadoras.

Os planos de saúde, constituindo-se em monopsônios ou em oligopsônios regionais, detêm forte poder de negociação perante os hospitais, influenciando os preços, $e$ a pressão exercida, ao longo do tempo, tende a reduzir a rentabilidade dos hospitais, comprometendo a qualidade dos serviços e a continuidade dos negócios. Diante disso, a fixação dos preços dos serviços hospitalares, com base nos custos, vem sendo inviabilizada pelo ambiente altamente competitivo e, principalmente, pela imposição dos preços desses serviços pelos planos de saúde.

Com relação aos custos hospitalares, Ray (2001, p. 42) afirma que qualquer serviço ou produto hospitalar tem entre $20 \%$ e $30 \%$ de custos desnecessários, cujos recursos não adicionam valor e, portanto, poderiam ser eliminados sem afetar seus atributos.

Além disso, a literatura existente, com exceção da dissertação de mestrado de Hansen ${ }^{1}$, contempla a utilização do Custeio-alvo exclusivamente em indústrias auto- mobilísticas, eletrônicas, de softwares de computadores e outras que operam em ambientes de alta tecnologia. Não há evidências do uso do Custeio-alvo em serviços hospitalares.

Nesse contexto, formulam-se as seguintes questões de pesquisa:

a) o processo do Custeio-alvo é aplicável em entidades hospitalares?

b) que aspectos do Custeio-alvo, observados durante o processo de aplicação a serviços hospitalares não são contemplados na literatura existente?

Assim, o objetivo deste estudo foi testar a aplicabilidade do processo de Custeio-alvo em entidades e produtos hospitalares e, para isso, optou-se por uma pesquisa exploratória do tipo estudo de caso único. Utilizaram-se como fontes de dados: levantamento bibliográfico, questionário, entrevistas, observação direta dos processos e atividades e relatórios contábeis, financeiros e administrativos da entidade objeto do estudo de caso.

Como entidade objeto de estudo, foi selecionado um hospital da cidade de Maringá-PR e, como produto da pesquisa, o parto com cesariana ${ }^{2}$ via planos de saúde, com internação em apartamento Standard ${ }^{3}$. Os dados utilizados referem-se ao ano de 2003.

Como delimitação, a pesquisa não entrou no mérito dos métodos de custeio utilizados pela entidade; tampouco se ocupou em verificar se as margens de lucro estabelecidas como metas eram ou não consistentes com seus planos estratégico e operacional.

\section{PLATAFORMA TEÓRICA}

Custeio-alvo é um instrumento da gestão estratégica de custos.

Sakurai (1997, p. 49) discorre sobre o Custeio-alvo como um método abrangente de gerenciamento estratégico de custos; portanto, a utilização do Custeio-alvo pelo segmento hospitalar pode representar uma poderosa ferramenta gerencial, vista sob esse enfoque.

Para Camacho (2004, p. 18), "o Custeio-alvo é um processo de gerenciamento de custos por meio do qual se busca o alcance do custo-alvo"; visa, fundamentalmente, ao alcance do lucro. Sendo o lucro a variável dependente das receitas e dos custos e considerando-se que o Custeio-alvo é fortemente recomendável em situações em que exista pouca ou ne- nhuma possibilidade de gestão dos preços (receitas), resta, como opção, concentrar esforços na gestão dos custos.

Com relação ao conceito do custo-alvo, Rocha (1999, p. 126), define:

Custo-alvo é o montante de custos que deve ser eliminado, ou aumentado, para que o custo estimado de um produto, ou serviço, se ajuste ao permitido, tendo em vista o custo de uso e de propriedade para o consumidor, o preço-alvo e as margens objetivadas para cada elo da cadeia.

Logo, custo-alvo é a diferença, ou o gap, entre o custo estimado e o máximo permitido. Dessa forma, o produto

\footnotetext{
1 Jens Erik Hansen defendeu a dissertação de mestrado com o título "Aplicação do Custeio-alvo em Cursos de Pós-Graduação Lato Sensu - Um estudo sob o enfoque da gestão estratégica de custos", sob a orientação do Professor Doutor Welington Rocha, na FEA/USP, no ano de 2002.

2 Cesariana considerada normal, ou seja, aquela na qual o retorno à saúde tanto da parturiente quanto do bebê ocorrem dentro do esperado. O período de internação é, em média, de 2 dias e não há necessidade do uso de medicamentos, materiais, equipamentos ou instalações, além daqueles normalmente utilizados.

3 Para a entidade pesquisada, o apartamento Standard possui um único leito e banheiro próprio. Além disso, está equipado com aparelho televisor, aparelho telefônico e ventilador de teto.
} 
apenas entraria em processo de produção quando o custoalvo fosse igual ou próximo a zero.

Com o objetivo de demonstrar o conceito do custoalvo, elaborou-se um exemplo numérico, evidenciando-o na Tabela 10.

Justifica-se o uso desse termo, pois essa diferença é móvel, assim como pode ser um alvo. Isso significa que a diferença vai se modificando à medida que são feitas alterações no projeto e no custo estimado.

\section{1 processo de Custeio-alvo}

Segundo Hansen (2002, p. 27), o planejamento de um novo produto e a definição do seu custo-alvo é um processo composto de sete fases; cada uma destas fases é explicada a seguir:

Pesquisa de mercado. Fornece informações sobre necessidades e anseios dos consumidores, define o mercado e o nicho de produtos que a empresa pretende explorar.

Análise da competitividade do mercado. Fornece informações a respeito dos produtos concorrentes, como os consumidores avaliam esses produtos e como os concorrentes reagirão ao lançamento de novos produtos.
Definição do produto e do nicho de consumidores. Baseado na pesquisa de mercado e conhecendo a competitividade do setor, determina-se qual produto será produzido e para qual nicho de consumidores será direcionado.

Captação dos desejos e necessidade dos consumidores. Pressupõe colher informações dos consumidores que orientem o desenvolvimento de novos produtos.

Definição das características do produto. Uma vez conhecidas as necessidades dos consumidores, são definidas as características do produto bem como o seu nível de desempenho para atender essas necessidades.

Preço de mercado. Representa o preço que os consumidores estariam dispostos a pagar.

Margem desejada. É o retorno econômico esperado do produto. Pode ser a Margem de Contribuição, a Margem Bruta ou Margem Operacional, dependendo do método de custeio utilizado, e pode ser expressa tanto em valores absolutos como em percentual sobre as vendas.

Custo máximo admissível. É a diferença entre o preço de mercado e a margem desejada. Deve ser comparado com o custo estimado e a diferença entre ambos, que é o custoalvo, representa o valor que deverá ser ajustado antes que o produto entre no processo de produção.

\section{O PROCESSO DE CUSTEIO-ALVO NA EMPRESA PESOUISADA}

\subsection{Definição do Preço-alvo e da Margem Objetivada para o Pacote Cesariana ${ }^{4}$}

Como preço-alvo do pacote foi utilizado um valor hipotético; é hipotético por não ter sido obtido por meio de ampla pesquisa junto aos planos de saúde. No entanto, estabeleceu-se um preço médio entre aqueles que os planos vinham oferecendo ao hospital pelo pacote cesariana ${ }^{5}$. O Preço-alvo do pacote foi definido em $\mathrm{R} \$ 800,00^{6}$ (oitocentos reais), independentemente do volume de cesarianas realizadas. A maioria dos planos de saúde que mantêm convênio com o hospital opera com prazos médios que variam entre 40 e 50 dias para pagamento das faturas; contudo, neste trabalho, para simplificar didaticamente o processo de Custeio-alvo, o preço dado será considerado como se fosse à vista ${ }^{7}$.

A direção da empresa sugeriu trabalhar com 22,5\% de Margem Operacional-alvo, aplicados sobre o preço de venda líquido; a partir daí, foi possível calcular a Margem Operacional-alvo em valor absoluto, demonstrada na Tabela 20 .

\subsection{Cálculo do Custo Máximo Admissivel por Pacote}

Conhecidos o preço-alvo e a margem objetivada, o próximo passo foi calcular o custo máximo admissível, que

\section{Tabela 1 || Custo-alvo}

\begin{tabular}{c|c} 
Componentes & Valor \\
\hline Preço de venda & 100 \\
\hline Lucro meta (10\%) & 10 \\
\hline $\begin{array}{c}\text { Custo máximo } \\
\text { admissível }\end{array}$ & 90 \\
\hline Custo estimado & 93 \\
\hline Custo-alvo (Gap) & $\mathbf{( 3 )}$
\end{tabular}

4 No pacote cesariana estão inclusos as diárias, as taxas e todos os medicamentos e materiais consumidos, exceto os honorários médicos - O plano de saúde paga um único valor pelo pacote todo.

5 Como os custos estimados referem-se ao ano de 2003, esse preço também é relativo ao mesmo ano.

6 Preço bruto (impostos inclusos).

7 O correto é trazer o preço a prazo a valor presente. 
Tabela 2 || Cálculo da Margem Operacional Objetivada por pacote

\begin{tabular}{|l|c}
\hline Descrição & Valor \\
Preço de Venda Bruto & 800,00 \\
\hline (-) Impostos $7,03 \% \%^{8}$ & 56,24 \\
\hline (=) Preço de Venda Líquido & 743,76 \\
\hline Margem Operacional-alvo $(743,76 \times 1 .$. \\
\hline
\end{tabular}

consiste em confrontar o preço de venda líquido com a margem objetivada.

O valor de $\mathrm{R} \$ 576,41$ representa o custo máximo admissível para se obter a margem de lucro desejada de $\mathrm{R} \$ 167,35$, em função do preço-alvo bruto de mercado de $\mathrm{R} \$ 800,00$ (Tabela 3).

\subsection{Cálculo do Custo Estimado (CE)}

Para se estimar o custo do pacote cesariana, deve-se computar todos os recursos materiais e humanos para o atendimento da paciente e do bebê identificando-se, de forma detalhada, os recursos relevantes e, em seguida, custeá-los (Tabela 4).

\subsection{Comparação do Custo Máximo Admissivel com o Custo Estimado}

Conhecido o custo estimado do pacote, o passo seguinte foi compará-lo ao máximo admissível, para obtenção do custo-alvo (Tabela 5).

\subsection{Aplicação da Engenharia do} Valor (EV) para eliminar o Custo-alvo

Quando a diferença (gap) entre o Custo Máximo e o Estimado é menor que zero $(576,41$ - 615,43 = -39,02), deve-se decompor o produto ou serviço em necessidades funcionais e, para tanto, utilizou-se de técnicas de Engenharia do Valor; isso permitiu a alteração do projeto do serviço, visando a eliminar o Custo-alvo de $R \$ 39,02$.

Nessa etapa, utilizou-se a pesquisa realizada com o grupo de 50 mulheres para avaliar o grau de importância por elas atribuído a cada atributo do serviço (parto cesariana). Cada atributo foi pontuado de 1 a 4 conforme a escala Likert (4 - muito importante; 3 - importante; 2 - pouco importante; 1 - dispensável). As respostas foram tabuladas em termos absolutos, ou seja, a quantidade de respondentes em cada opção de resposta; depois, transformadas em termos percentuais. Por último,

Tabela 3 | Cálculo do Custo Máximo do pacote - em Reais

\begin{tabular}{l|c} 
Descrição & Valor \\
Preço de venda líquido & 743,76 \\
\hline (-) Margem operacional desejada & 167,35 \\
\hline (=) Custo Máximo admissível & 576,41
\end{tabular}

Tabela 4 Custo Estimado do pacote cesariana - em Reais

\begin{tabular}{|l|c|c|}
\hline Componente & Valor & $\%$ \\
\hline Materiais hospitalares & 98,64 & $16,03 \%$ \\
\hline Medicamentos hospitalares & 48,31 & $7,85 \%$ \\
\hline Diárias apartamento Standard (2 dias) & 200,16 & $32,52 \%$ \\
\hline Diárias berçário (2 dias) & 157,32 & $25,56 \%$ \\
\hline Taxa de uso de sala centro cirúrgico (2 horas) & 111,00 & $18,04 \%$ \\
\hline Total & $\mathbf{6 1 5 , 4 3}$ & $\mathbf{1 0 0 , 0 0}$ \\
\hline
\end{tabular}

Tabela 5 || Comparação do Custo Estimado com o Custo-meta do pacote

\begin{tabular}{|c|c|}
\hline Descrição & Valor \\
\hline Custo Estimado (Tabela 4) & 615,43 \\
\hline Custo máximo admissível (Tabela 3) & 576,41 \\
\hline Custo-alvo em Reais & 39,02 \\
\hline Custo-alvo em \% do estimado & $6,34 \%$ \\
\hline
\end{tabular}

8 Imposto Sobre Serviços - ISS = 3\%; Programa de Integração Social - PIS = 0,65\%; Contribuição para o Financiamento da Seguridade Social - COFINS = 3,0\%; Contribuição
Provisória sobre Movimentação Financeira - CPMF =0,38\%. Alíquotas vigentes à época da realização da pesquisa.

9 A entidade pesquisada utiliza o Custeio-pleno para o cálculo do custo estimado. 
calculou-se a média ponderada, considerando-se o percentual de respondentes em cada opção e o respectivo grau de importância.

Os atributos, com seus respectivos graus de importância, estão listados na Tabela $6 \mathbf{0}$.

O próximo passo foi a identificação dos recursos necessários para atender cada um dos atributos do serviço. Foram, então, extraídos da Tabela 6 todos os atributos que pudessem ser relacionados com recursos e seus respectivos custos, em um total de quatorze. Esses atributos foram, primeiramente, agrupados em dois blocos: os relacionados à cirurgia e os relacionados à diária hospitalar. Em seguida, foi calculado o grau de Importância Relativa (IR) de cada recurso, conforme demonstrado na Tabela $7 \boldsymbol{\theta}$.
Os atributos relacionados à cirurgia foram agrupados e tiveram seus graus de importância somados, pois seu atendimento depende, basicamente, dos 'materiais' e 'medicamentos'. Além disso, o grau de importância de cada um deles é muito próximo um do outro.

Os termos 'grau de importância relativa do atributo' e 'grau de importância relativa do recurso (IR)' (Tabela 7), bem como "Custo Relativo" (CR) e "Índice de Valor" (IV) (Tabela 8) são explicados a seguir.

Grau de Importância Relativa do Atributo

Representa, em termos proporcionais, sob a ótica dos consumidores, o quão importante é o atributo, no conjunto de atributos. É medido pela seguinte fórmula:

\section{Grau de importância $\%=\frac{\text { Grau de importância do atributo para as mulheres }}{\text { Total dos graus de importância dos atributos para as mulheres }}$}

Veja-se o cálculo do grau de importância relativa do atributo 'instalações asseadas':

$$
\text { Grau de importância do atributo 'instalações asseadas' } \%=\frac{3,92}{48,4400} \times 100=8,09 \%
$$

Grau de Importância Relativa do Recurso (IR)

Representa, em termos proporcionais, o quanto cada recurso é importante dentro do conjunto de recursos, considerando-se o grau de importância do respectivo atributo, ponderado pela sua contribuição para prover aquele atributo.

Tabela 6 Grau de importância dos atributos da cesariana

\begin{tabular}{|c|c|c|c|c|c|}
\hline Itens & 4 & 3 & 2 & 1 & $\begin{array}{l}\text { Grau de impor- } \\
\text { tância para as } \\
\text { mulheres }^{10}\end{array}$ \\
\hline \multicolumn{6}{|l|}{ Relacionados à cirurgia } \\
\hline - Não sentir dor durante nem após a cirurgia & 3,4400 & 0,4200 & 0,0000 & 0,0000 & 3,8600 \\
\hline - Não sentir náuseas após a cirurgia & 2,9600 & 0,6600 & 0,0800 & 0,0000 & 3,7000 \\
\hline $\begin{array}{l}\text { - Retorno progressivo à saúde da parturiente - contração do } \\
\text { útero, cicatrização normal, não contrair infecção etc. }\end{array}$ & 3,9200 & 0,0600 & 0,0000 & 0,0000 & 3,9800 \\
\hline - Imediata identificação da mãe e bebê & 3,8400 & 0,1200 & 0,0000 & 0,0000 & 3,9600 \\
\hline $\begin{array}{l}\text { - Retorno progressivo à saúde do bebê - cicatrização do umbi- } \\
\text { go etc. }\end{array}$ & 3,6800 & 0,2400 & 0,0000 & 0,0000 & 3,9200 \\
\hline \multicolumn{6}{|l|}{ Relacionados à internação } \\
\hline - O bebê ficar no mesmo quarto que a mãe & 2,4800 & 0,9000 & 0,1200 & 0,0200 & 3,5200 \\
\hline - Instalações asseadas & 3,6800 & 0,2400 & 0,0000 & 0,0000 & 3,9200 \\
\hline - Roupas de cama e banho limpas & 3,4400 & 0,4200 & 0,0000 & 0,0000 & 3,8600 \\
\hline - Serviço de psicologia hospitalar para a parturiente & 1,5200 & 1,5600 & 0,1600 & 0,0200 & 3,2600 \\
\hline - Alimentação & 1,8400 & 1,4400 & 0,1200 & 0,0000 & 3,4000 \\
\hline - Enfermagem eficiente e cordial & 3,3600 & 0,4800 & 0,0000 & 0,0000 & 3,8400 \\
\hline - Recepção e check-out rápido e cordial & 2,3200 & 1,0800 & 0,0800 & 0,0200 & 3,5000 \\
\hline - Entretenimento & 0,1600 & 0,5400 & 0,9600 & 0,3000 & 1,9600 \\
\hline - Ambiente climatizado & 0,9600 & 1,3800 & 0,5200 & 0,0400 & 2,9000 \\
\hline - Frigobar & 0,5600 & 0,9000 & 0,7200 & 0,2000 & 2,3800 \\
\hline
\end{tabular}


Tabela 7 Grau de Importância Relativa (IR) dos recursos necessários para atender aos atributos da cesariana

\begin{tabular}{|c|c|c|c|c|c|}
\hline Itens/Atributos & $\begin{array}{l}\text { Grau de } \\
\text { importân- } \\
\text { cia dos } \\
\text { atributos } \\
\text { para as } \\
\text { mulheres }\end{array}$ & $\begin{array}{l}\text { Grau de } \\
\text { Importân- } \\
\text { cia relativa } \\
\text { dos atribu- } \\
\text { tos (em \%) }\end{array}$ & Recursos utilizados & $\begin{array}{l}\text { Percentual } \\
\text { de contri- } \\
\text { buição em } \\
\text { relação ao } \\
\text { atributo }\end{array}$ & $\begin{array}{l}\text { Grau de Im- } \\
\text { portância } \\
\text { relativa dos } \\
\text { recursos } \\
\text { (IR) em (\%) }\end{array}$ \\
\hline \multicolumn{6}{|l|}{ Relacionados à cirurgia } \\
\hline $\begin{array}{l}\text { - Não sentir dor durante nem após a } \\
\text { cirurgia } \\
\text { - Não sentir náuseas após a cirurgia } \\
\text { - Retorno progressivo à saúde da } \\
\text { parturiente - contração do útero, } \\
\text { cicatrização normal, não contrair } \\
\text { infecção etc. } \\
\text { - Imediata identificação da mãe e } \\
\text { bebê } \\
\text { - Retorno progressivo à saúde do } \\
\text { bebê - cicatrização do umbigo etc. }\end{array}$ & $\begin{array}{l}3,8600 \\
3,7000 \\
3,9800\end{array}$ & & $\begin{array}{l}\text { Materiais } \\
\text { Medicamentos } \\
\text { Pessoal de enfermagem } \\
\text { Materiais esterilizados } \\
\text { Energia Elétrica Centro } \\
\text { Cirúrgico } \\
\text { Depreciação Centro } \\
\text { Cirúrgico }\end{array}$ & $\begin{array}{r}30 \\
60 \\
5 \\
5 \\
0 \\
0\end{array}$ & $\begin{array}{c}12,03 \% \\
24,06 \% \\
2,00 \% \\
2,00 \% \\
0,00 \% \\
0,00 \%\end{array}$ \\
\hline Sub total & 19,4200 & $40,09 \%$ & & & \\
\hline \multicolumn{6}{|l|}{ Relacionados à internação } \\
\hline - Instalações asseadas & 3,9200 & $8,09 \%$ & $\begin{array}{l}\text { Pessoal de limpeza } \\
\text { Materiais de limpeza }\end{array}$ & $\begin{array}{l}60 \\
40\end{array}$ & $\begin{array}{l}4,85 \% \\
3,24 \%\end{array}$ \\
\hline - Roupas de cama e banho limpas & 3,8600 & $7,97 \%$ & $\begin{array}{l}\text { Produtos de lavanderia } \\
\text { Água da lavanderia } \\
\text { Energia elétrica } \\
\text { Lavanderia } \\
\text { Pessoal de lavanderia } \\
\text { Outros custos lavanderia }\end{array}$ & $\begin{array}{r}50 \\
20 \\
10 \\
15 \\
5 \\
0 \\
\end{array}$ & $\begin{array}{l}3,98 \% \\
1,59 \% \\
0,80 \% \\
1,20 \% \\
0,40 \% \\
0,00 \% \\
\end{array}$ \\
\hline $\begin{array}{l}\text { - Serviço de psicologia hospitalar } \\
\text { para a parturiente }\end{array}$ & 3,2600 & $6,73 \%$ & Pessoal psicologia & 100 & $6,73 \%$ \\
\hline - Alimentação & 3,4000 & $7,02 \%$ & $\begin{array}{l}\text { Gêneros alimentícios } \\
\text { Pessoal da cozinha } \\
\text { Outros custos da } \\
\text { cozinha }\end{array}$ & $\begin{array}{r}80 \\
15 \\
5\end{array}$ & $\begin{array}{l}5,62 \% \\
1,05 \% \\
0,35 \%\end{array}$ \\
\hline - Enfermagem eficiente e cordial & 3,8400 & $7,93 \%$ & Pessoal de enfermagem & 100 & $7,93 \%$ \\
\hline $\begin{array}{l}\text { - Recepção e check-out rápido e } \\
\text { cordial }\end{array}$ & 3,5000 & $7,23 \%$ & $\begin{array}{l}\text { Pessoal de recepção } \\
\text { Outras despesas de } \\
\text { recepção }\end{array}$ & $\begin{array}{r}95 \\
5\end{array}$ & $\begin{array}{l}6,87 \% \\
0,36 \%\end{array}$ \\
\hline - Entretenimento & 1,9600 & $4,05 \%$ & TV - Depreciação & 100 & $4,05 \%$ \\
\hline - Ambiente climatizado & 2,9000 & $5,98 \%$ & Ar-Cond. - Depreciação & 100 & $5,98 \%$ \\
\hline - Frigobar & 2,3800 & $4,91 \%$ & Frigobar - Depreciação & 100 & $4,91 \%$ \\
\hline Total & 48,4400 & $100,00 \%$ & & & $100,00 \%$ \\
\hline
\end{tabular}

É resultante da multiplicação do Grau de Importância Relativa do Atributo pelo percentual de contribuição do recurso. Exemplificando, o IR do recurso 'medicamentos' foi obtido pela multiplicação de $40,09 \%$ (grau de importância em \%) por 60\% (contribuição do recurso para o atributo), o que resultou em $24,06 \%$ de IR.

\section{Custo Relativo (CR)}

O Custo Relativo (CR) de cada recurso mede, em termos proporcionais, o quanto seu custo representa em relação ao custo total dos recursos.

Índice de Valor (IV)

O Índice de Valor (IV) de cada recurso é obtido pela divisão do IR pelo CR. Representa a relação entre a impor- 
tância relativa de um recurso e seu custo relativo. Índices de Valor acima de 1 significam que o Custo Relativo do recurso é menor que o seu grau de importância relativa $e$ IV abaixo de 1 significa que o Custo Relativo do recurso é superior ao seu grau de importância relativa. O objetivo é que o IV fique próximo a 1, alcançando, assim, uma situação de equilíbrio entre as funções do recurso e seu respectivo custo.

O cálculo do CR e do IV dos recursos do pacote cesariana é demonstrado na Tabela 80 .

\subsection{Modificação no projeto do Pacote}

A equipe, de posse dessas informações, reuniu-se, com o objetivo de encontrar alternativas para eliminar o gap de $R \$ 39,02$ e limitar o custo ao máximo permissível de $\mathrm{R} \$ 576,41$.

Inicialmente, concentrou-se no custo dos recursos que apresentavam Índices de Valor menores que $1^{11} \mathrm{e}$, visando a obter resultados significativos, decidiu concentrar esforços nos itens de custos relevantes. Assim, foram selecionados e analisados os recursos: 'materiais', 'pessoal de enfermagem' e 'outras despesas administrativas gerais' cuja soma, $R \$ 409,67^{12}$, representava $66,5 \%$ do custo estimado total $(\mathrm{R} \$ 615,43)$. Isso não quer dizer que tenha havido um retorno à análise tradicional de custos, na qual os itens relevantes são os candidatos a reduções; nesse caso, antes disso, o observou-se o IV do recurso, que reflete a voz do consumidor. O recurso 'medicamentos', por exemplo,

Tabela 8 Custo Relativo (CR) e Índice de Valor (IV) dos recursos

\begin{tabular}{|c|c|c|c|c|}
\hline Recursos utilizados & Custo em R\$ & CR & IR & IV \\
\hline Materiais & 98,64 & $16,03 \%$ & $12,03 \%$ & 0,75 \\
\hline Medicamentos & 48,31 & $7,85 \%$ & $24,06 \%$ & 3,07 \\
\hline Esterilização de materiais & 18,63 & $3,03 \%$ & $2,00 \%$ & 0,66 \\
\hline Pessoal de enfermagem & 194,26 & $31,56 \%$ & $9,93 \%$ & 0,31 \\
\hline Pessoal de limpeza & 14,14 & $2,30 \%$ & $4,85 \%$ & 2,11 \\
\hline Pessoal de manutenção (*) & 7,42 & $1,21 \%$ & $0,00 \%$ & 0,00 \\
\hline Pessoal de psicologia & 4,69 & $0,76 \%$ & $6,73 \%$ & 8,83 \\
\hline Pessoal de lavanderia & 11,19 & $1,82 \%$ & $1,20 \%$ & 0,66 \\
\hline Pessoal de cozinha & 8,23 & $1,34 \%$ & $1,05 \%$ & 0,79 \\
\hline Pessoal de recepção & 15,91 & $2,59 \%$ & $6,87 \%$ & 2,66 \\
\hline Material de manutenção $\left(^{*}\right)$ & 13,54 & $2,20 \%$ & $0,00 \%$ & 0,00 \\
\hline Material de limpeza & 5,55 & $0,90 \%$ & $3,24 \%$ & 3,59 \\
\hline Produtos para lavanderia & 5,97 & $0,97 \%$ & $3,98 \%$ & 4,10 \\
\hline Água lavanderia & 4,48 & $0,73 \%$ & $1,59 \%$ & 2,18 \\
\hline Gêneros alimentícios & 12,63 & $2,05 \%$ & $5,62 \%$ & 2,74 \\
\hline Energia elétrica do Centro Cirúrgico (*) & 2,34 & $0,38 \%$ & $0,00 \%$ & 0,00 \\
\hline Energia elétrica da lavanderia & 2,63 & $0,43 \%$ & $0,80 \%$ & 1,87 \\
\hline Energia elétrica $\left({ }^{*}\right)$ & 3,16 & $0,51 \%$ & $0,00 \%$ & 0,00 \\
\hline Material de expediente $\left.{ }^{*}{ }^{*}\right)$ & 7,73 & $1,26 \%$ & $0,00 \%$ & 0,00 \\
\hline Água (*) & 2,81 & $0,46 \%$ & $0,00 \%$ & 0,00 \\
\hline Depreciação (prédio, móveis, equip. C. Cirúrgico) (*) & 4,79 & $0,78 \%$ & $0,00 \%$ & 0,00 \\
\hline Depreciação (prédio, móveis, equip. maternidade) $\left(^{*}\right)$ & 2,34 & $0,38 \%$ & $0,00 \%$ & 0,00 \\
\hline Depreciação (prédio, móveis, equip. berçário) (*) & 1,39 & $0,23 \%$ & $0,00 \%$ & 0,00 \\
\hline Depreciação do televisor & 0,02 & $0,00 \%$ & $4,05 \%$ & $1.246,25$ \\
\hline Depreciação do condicionador de ar & 0,09 & $0,01 \%$ & $5,98 \%$ & 408,92 \\
\hline Depreciação do frigobar & 0,01 & $0,00 \%$ & $4,91 \%$ & $3.021,76$ \\
\hline Outros custos diretos C. Cirúrgico $\left(^{*}\right)$ & 1,81 & $0,29 \%$ & $0,00 \%$ & 0,00 \\
\hline Outros custos da lavanderia & 0,62 & $0,10 \%$ & $0,40 \%$ & 3,97 \\
\hline Outros custos da maternidade $\left({ }^{*}\right)$ & 1,53 & $0,25 \%$ & $0,00 \%$ & 0,00 \\
\hline Outros custos do berçário (*) & 0,93 & $0,15 \%$ & $0,00 \%$ & 0,00 \\
\hline Outros custos da cozinha & 0,92 & $0,15 \%$ & $0,35 \%$ & 2,34 \\
\hline Outras despesas de recepção & 1,95 & $0,32 \%$ & $0,36 \%$ & 1,14 \\
\hline Outras despesas administrativas gerais $(*)$ & 116,77 & $18,97 \%$ & $0,00 \%$ & 0,00 \\
\hline Total & 615,43 & & & \\
\hline
\end{tabular}

(*) estes itens representam recursos que, de acordo com o método de custeio adotado pelo hospital (Custeio-pleno), são consumidos no fornecimento do serviço, porém não puderam ser relacionados com nenhum atributo em particular. 
mesmo representando $7,85 \%$ do custo total, não era passível de redução, pois apresentava IV $=3,07$.

Quanto aos materiais, analisou-se, cuidadosamente, cada item. Com exceção dos fios para sutura, todos os demais estavam com preços mais baixos ou iguais aos dos fornecedores concorrentes. Assim, a análise concentrou-se nos fios para sutura. A equipe tinha esperanças de conseguir significativa redução de custo nesse item, uma vez que o seu valor $(R \$ 59,58)$ representava $60,4 \%$ do custo total com materiais $(\mathrm{R} \$ 98,64)$. Para esse item, o hospital possui um fornecedor exclusivo, líder do mercado, que comercializa todos os tipos de fios e que sempre garantiu preços menores que seu concorrente e; além disso, era o único que fabricava fios absorvíveis ${ }^{13}$ de origem sintética.

Descartada a possibilidade de mudar de fornecedor, aventou-se a de usar fios absorvíveis de origem animal em lugar do sintético. Ao todo, utilizam-se quatro envelopes de fio absorvível sintético, ao custo unitário de $R \$ 6,99$, perfazendo um total de $R \$ 27,96$. O custo unitário do absorvível de origem animal é de $R \$ 4,25$, representando $R \$ 17,00$ no total; portanto, uma economia significativa. No entanto, isso representava uma mudança no projeto do serviço e era necessário o parecer de um médico obstetra.

O parecer frustrou as expectativas da equipe. Segundo os médicos, os resultados são melhores quando se usa o fio sintético: com ele, as reações inflamatórias são menores ou inexistentes e apresentam sempre o mesmo poder de tensão, o que não é garantido pelos de origem animal. Assim, apesar de não se ter conseguido reduções de custos nos materiais, a equipe deu-se por satisfeita, pois o importante é manter-se dentro dos parâmetros de qualidade estabelecidos.

Com relação ao recurso 'pessoal de enfermagem', cujo Índice de Valor era 0,31, foi possível obter redução de custo, com a modificação do projeto do serviço. Dentre os atributos avaliados pelas mulheres, encontra-se 'o bebê ficar no mesmo quarto que a mãe', cujo grau de importância é 3,52 (Tabela 6). Atualmente, os bebês ficam no berçário, separados das mães. Não haveria custo adicional para atender a esse atributo; ao contrário, com os bebês passando o tempo todo ao lado das mães, é possível reduzir o tempo e a quantidade de enfermeiras lotadas no berçário. O número de enfermeiras por leito é uma informação que o hospital não revelou; contudo a modificação no projeto do serviço permitiria a redução de, pelo menos, duas pessoas no quadro de enfermagem do berçário, sem prejudicar a qualidade do atendimento. A equipe estimou uma economia anual em torno de $\mathrm{R} \$ 32.846,00$ no berçário. Como a ocupação planejada do berçário para o ano é de 2.920 diárias, ao dividirmos os $\mathrm{R} \$ 32.846,00$ por 2.920 , obtêm-se $\mathrm{R} \$ 11,25$ de economia para cada diária; assim, para dois dias de internação, chegou-se à economia de $R \$ 22,50$.

Quanto às 'outras despesas administrativas gerais' que, de acordo com a Tabela 8, representam 18,97\% do custo total, e cujo IV era aproximadamente zero, a equipe verificou que só seria possível obter redução no custo modificando o projeto do serviço. O faturamento dos serviços prestados pelo sistema de pacotes simplifica, drasticamente, as tarefas dos setores de faturamento e emissão de guias do hospital. Com isso, seria possível reduzir em $50 \%$ o quadro funcional nessas áreas. A equipe estimou uma economia anual de $R \$ 77.032,00$ nesses setores. Desse montante, considerando-se os critérios de alocação de custos utilizados pela entidade, o custo anual da Maternidade seria reduzido em $R \$ 29.810,00\left(R \$ 10,20^{14}\right.$ no pacote), enquanto o custo anual do Berçário seria reduzido em $\mathrm{R} \$ 14.092,00$ ( $R \$ 9,66^{15}$ no pacote).

Os demais itens, cujo IV era menor que 1, não foram abordados. Teoricamente, cada item deveria ser analisado com o objetivo de reduzir custo; no entanto, por se tratar de itens com baixo custo em valor absoluto, as reduções conseguidas não seriam relevantes, ou seja, apesar de possíveis, as economias alcançadas seriam inferiores ao custo de obtê-las.

Com relação aos recursos cujo IV era maior que 1 , a equipe decidiu não tomar nenhuma providência. Nesses casos, o custo relativo do recurso é menor que sua importância relativa. Em outras palavras, são recursos com os quais se gasta relativamente pouco mas que trazem grandes benefícios para o consumidor. Dessa forma, desde que não se comprometesse a margem de lucroalvo, seria possível até mesmo aumentar os valores gastos com eles.

Antes de calcular o novo Custo Estimado, a equipe elaborou uma lista contendo as decisões tomadas, bem como as reduções de custos obtidas (Tabela 9).

Tabela 9 || Decisões tomadas e reduções de custos obtidas

\begin{tabular}{l|l|c} 
Decisões tomadas & \multicolumn{1}{|c}{ Recursos afetados } & \multicolumn{1}{c}{ Economia alcançada (R\$) } \\
Colocar o bebê no mesmo quarto com a mãe & Pessoal de enfermagem & $\begin{array}{l}\text { Outras despesas administrativas } \\
\text { gerais }\end{array}$ \\
\hline Alterar o projeto do serviço (cesariana) para o sistema de pacotes & & $\mathbf{4 2 , 3 6}$
\end{tabular}

13 Tipo de fio utilizado em suturas internas. Com o tempo esse fio é totalmente absorvido pelo organismo da pessoa.

$14 \mathrm{R} \$ 29.810,00$ dividido por 5.840 diárias estimadas anuais $=\mathrm{R} \$ 5,10$ por diária $\times 2$ diárias $=\mathrm{R} \$ 10,20$ no pacote.

$15 \mathrm{R} \$ 14.092,00$ dividido por 2.920 diárias estimadas anuais $=\mathrm{R} \$ 4,83$ por diária $\times 2$ diárias $=\mathrm{R} \$ 9,66$ no pacote. 


\subsection{Recálculo do Custo Estimado}

Em face das alterações realizadas, elaborou-se uma nova estimativa dos custos para verificar se o custo máximo admissível havia sido atingido, conforme demonstrado na Tabela $10 \boldsymbol{0}$.

As alterações tiveram reflexo direto no custo das diárias hospitalares do apartamento e do berçário: o custo dos dois dias de internação caiu de $R \$ 200,16$ para $R \$ 189,96$ nos apartamentos e de $R \$ 157,32$ para $R \$ 125,16$ no berçário. O custo dos demais componentes (medicamentos, materiais e taxa de uso de sala do centro cirúrgico) permaneceu constante.

\subsection{Comparação do Custo Máximo} Admissível com o Novo Custo Estimado

A pequena diferença, de $R \$ 3,34$, significa que o custoalvo foi superado (Tabela 11).

\subsection{Relançamento do produto}

Na Tabela $12 \mathbf{0}$, a equipe elaborou uma Demonstração Sintetizada do Resultado alcançado.

Uma vez que a Margem-alvo de 22,5\% foi superada, o produto pôde ser relançado no mercado. A equipe julgou ainda que, por se tratar de um serviço prestado exclusivamente a planos de saúde, não havia necessidade de estimar nenhum valor a título de inadimplência. Caso existisse um histórico de perdas nos recebíveis, elas deveriam ser esti- madas e computadas; e se a previsão para perdas afetasse a Margem-alvo, seria necessário recalcular um novo Custoalvo e o processo do Custeio-alvo seria retomado desde o início.

\subsection{Considerações sobre a aplicação do Custeio-alvo em entidades hospitalares}

No estudo em questão, exceto materiais e medicamentos, praticamente todos os demais custos são fixos; esse fato contribuiu para a decisão do hospital em trabalhar com o Custeio-pleno. Os autores do presente trabalho não discutiram o mérito de essa decisão estar ou não influenciada por possíveis paradigmas que possam explicar a adoção desse método de custeio. Pelo Custeio-pleno, todos os custos, fixos e variáveis, inclusive os de administração, são apropriados e alocados aos produtos. Isso tornou difícil a tarefa de relacionar certos recursos aos atributos.

A implementação do Custeio-alvo requer a participação de várias áreas da empresa. A área de Marketing é responsável pela pesquisa de mercado; Controladoria pela elaboração das planilhas de custos; Compras, por estabelecer limites de preços dos componentes de custos; Enfermagem, na reestruturação de seu quadro funcional para ficar compatível com a estrutura de leitos montada após as modificações implementadas e Diretoria Administrativa coordenando reuniões da equipe e definindo o momento em que o Custeio-alvo atingiu o patamar aceitável.

Tabela 10 Novo Custo Estimado do pacote cesariana - em Reais

\begin{tabular}{l|c}
\multicolumn{1}{c|}{ Componente } & Valor \\
Materiais hospitalares & 98,64 \\
\hline Medicamentos hospitalares & 48,31 \\
\hline Diárias apartamento Standard & 189,96 \\
\hline Diárias berçário & 125,16 \\
\hline Taxa de uso de sala centro cirúrgico & 111,00 \\
\hline Total & $\mathbf{5 7 3 , 0 7}$
\end{tabular}

Tabela 11 Comparação entre o Novo Custo Estimado e o Custo Máximo Admissível

\begin{tabular}{l|c}
\multicolumn{1}{c|}{ Descrição } & Valor \\
\hline Novo Custo Estimado & 573,07 \\
\hline Custo máximo admissível & 576,41 \\
\hline Custo-alvo em Reais & $\mathbf{( 3 , 3 4 )}$ \\
\hline Custo-alvo em \% do estimado & $\mathbf{0 , 5 8 \%}$
\end{tabular}

Tabela 12 || Demonstração Sintetizada de Resultados

\begin{tabular}{l|c} 
Descrição & Valor \\
Preço de venda & 800,00 \\
\hline (-) impostos 7,03\% & 56,24 \\
\hline (=) Preço de venda líquido & 743,76 \\
\hline (-) Custos Estimados & 573,07 \\
\hline (=) Margem operacional - em Reais & $\mathbf{1 7 0 , 6 9}$ \\
\hline (=) Margem operacional - em \% & $\mathbf{2 2 , 9 5 \%}$
\end{tabular}


No Custeio-alvo, a voz do consumidor deve orientar todo o processo. Isso ficou evidente quando o recurso 'medicamentos', que representava $7,85 \%$ do custo total da cesariana, não foi objeto de redução. Na forma tradicional de gestão de custos, esse item seria um candidato a sofrer cortes, talvez utilizando-se medicamentos genéricos, mais baratos. Contudo, sob a ótica do Custeio-alvo, deveria acontecer justamente o contrário, ou seja, poder-se-ia até gastar mais com medicamentos, uma vez que se trata de um recurso vinculado a um atributo muito valorizado pelos consumidores.

A literatura pesquisada, embora tenha fornecido subsídios para compreender e explicar o processo de implantação do Custeio-alvo em produtos e serviços hospitalares, aborda, predominantemente, o uso do Custeio-alvo pelas indústrias de manufatura. Nesse sentido, alguns aspectos relevantes devem ser considerados em relação à comparação entre o Custeio-alvo, tal como é descrito na literatura pesquisada, e sua adequação a produtos e serviços hospitalares. Ao comparar o processo de aplicação do Custeioalvo a serviços hospitalares com a literatura pesquisada, constatou-se que existem aspectos que se assemelham $e$ outros que se diferenciam e, existem, ainda, aspectos que não são abordados pela literatura consultada.

Quanto aos aspectos que se assemelham aos encontrados na literatura pesquisada, podem-se citar:

- Existe um preço de mercado para os produtos e serviços hospitalares, tal como ocorre com produtos manufaturados. Apesar de parecer pouco comum, é possível determinar o preço dos produtos e serviços particulares através de pesquisa com potenciais pacientes. Quanto aos serviços prestados via planos de saúde, apesar de o preço dos produtos e serviços ser fixado em contrato, esse poderia ter como parâmetro os preços de mercado praticados com pacientes particulares.

- Tanto na indústria de manufatura quanto no segmento hospitalar, os critérios para definição da margem objetivada são os mesmos, ou seja, dependem do modelo de decisão dos gestores e dos planos estratégico e operacional da instituição. Dessa forma, o critério não se altera em função de ser estabelecido por indústrias de manufatura ou instituições hospitalares.

Quanto aos pontos nos quais foram percebidas as maiores diferenças na comparação da aplicação do Custeio-alvo em produtos e serviços hospitalares com sua aplicação no setor industrial, podem-se citar:

- Parece haver um número muito maior de atributos nos produtos e serviços hospitalares do que nos manufaturados. No parto com cesariana, foram selecionados 24 atributos, considerados importantes ou relevantes, conforme pode ser observado na Tabela 7 .

- O grau de manobra para a gestão de custos é, a princípio, menor no segmento hospitalar do que nas indústrias de manufatura. $\mathrm{Na}$ indústria, existe uma cadeia de valor muito mais ampla, facilitando a busca por produtos similares e possibilitando maior negociação com fornecedores. Além disso, na indústria parece haver maiores condições de modificação do projeto dos produtos através da criação de novas tecnologias, redução ou substituição de componentes, reestruturação do processo de produção, entre outros, do que em um produto ou serviço hospitalar.

- Percebeu-se que, no segmento hospitalar, existe maior dificuldade para relacionar os atributos do produto ou serviço com seus custos específicos. Isto se deve ao fato de a maioria dos recursos consumidos ter natureza fixa e serem indiretos em relação ao objeto de custeio (a cesariana). A literatura consultada mostra exemplos da aplicação do Custeio-alvo em empresas industriais, cujos atributos são, em sua maior parte, relacionados a componentes com custos diretamente alocados a eles.

\section{CONCLUSÃO}

Ao final da pesquisa, os autores concluíram que o processo de Custeio-alvo, descrito ao longo do tópico 3 , pode ser aplicado em entidades hospitalares. Destaque-se, como contribuição deste trabalho, não apenas a constatação da aplicabilidade desse artefato gerencial pelo segmento hospitalar, mas, principalmente, como aplicá-lo em uma situação específica.

Quanto aos aspectos da aplicação do Custeio-alvo a produtos e serviços hospitalares que não são encontrados na literatura consultada, saliente-se que ela não menciona como deve ser feito para se determinar a contribuição de cada recurso, em termos percentuais, no atendimento de determinada função ou atributo. Isso é necessário para se calcular a Importância Relativa do recurso utilizado, tal como foi demonstrado na Tabela 7. Para muitos atributos são necessários mais de um tipo de recurso (materiais, pessoal, energia elétrica etc.) e, nesse caso, depois de identificá-los, deve-se determinar o percentual de contribuição de cada um deles no atendimento do atributo ou função. A falta de um método apropriado pode levar à determinação de um percentual de participação do recurso no atendimento do atributo que não corresponda com a realidade operacional. Se isso for verdade, os resultados da utilização do Custeio-alvo, nesse segmento, podem ser afetados.

Além disso, sobre o método de custeio a ser utilizado no processo do Custeio-alvo, a literatura não diz qual seria o mais apropriado. Existem autores que defendem o 
uso do Custeio por Absorção, enquanto outros defendem a utilização do Custeio Direto, Activity Based Costing e até mesmo o Custeio Variável.

A utilização do Custeio-alvo pelo segmento hospitalar pode representar um diferencial significativo para que essas instituições tenham êxito no alcance de seus objetivos, no que se refere ao processo de gestão de custos.

Por se tratar de estudo de caso, a generalização deve ser em relação às proposições teóricas e não a populações ou universos. Isso quer dizer que não existe impedimento no sentido de se reproduzir esta pesquisa em outros hospitais, desde que obedecidas e melhoradas as técnicas e os métodos aqui utilizados. O que não se pode generalizar é, por exemplo, o grau de importância atribuído pelas mulhe- res aos atributos da cesariana, uma vez que isso foi obtido de uma amostra intencional, não aleatória.

A situação-problema, narrada nesta pesquisa, não é exclusiva dos hospitais privados; nos públicos, os problemas são tão ou mais graves. Os recursos são limitados e, na maioria das vezes, insuficientes. Diante disso, por que não se utilizar a filosofia, os princípios e a metodologia do Custeio-alvo também em hospitais públicos? Até mesmo hospitais sem fins lucrativos, públicos ou privados, deveriam sempre obter resultados econômicos positivos. Nada impede que tais entidades, inclusive as filantrópicas, aufiram superavits em suas atividades, os quais devem ser revertidos em benefício de seus objetivos assistenciais.

\section{Referências}

AGÊNCIA NACIONAL DE SAÚDE - ANS. Disponível em: <http://www.ans.gov.br>. Acesso em: 15 fẹv. 2004.

CAMACHO, R. R. Custeio-alvo em serviços hospitalares: um estudo sob o enfoque da gestão estratégica de custos. 2004. 166p. Dissertação (Mestrado em Controladoria e Contabilidade) - Faculdade de Economia, Administração e Contabilidade da Universidade de São Paulo, São Paulo.

HANSEN, J. E. Aplicação do custeio-alvo em cursos de pós-graduação lato sensu: um estudo sob o enfoque da gestão estratégica de custos. 2002. 211 p. Dissertação (Mestrado em Controladoria e Contabilidade) - Faculdade de Economia, Administração e Contabilidade da Universidade de São Paulo, São Paulo.

RAY, B. Value engineering: a practical approach to managing cost in critical care. Health Administrator. New Delhi. Issue 1, 2001. Disponivel em: <http://www.medind.nic.in>. Acesso em: 25 jul. 2004.

ROCHA, W. Contribuição ao estudo de um modelo conceitual de sistema de informação de gestão estratégica. 1999. 148p. Tese (Doutorado em Controladoria e Contabilidade) - Faculdade de Economia, Administração e Contabilidade da Universidade de São Paulo, São Paulo.

SAKURAI, M. Gerenciamento integrado de custos. São Paulo: Atlas, 1997.

\section{Bibliografia recomendada}

ANSARI, S. et al, Target costing: management accounting - a strategic focus. New York: McGraw-Hill, 1997a.

Target costing: the next frontier in strategic cost management. New York: McGraw-Hill, 1997b.

BHARAT, R. Value engineering: a new concept in reducing cost of burn care. Health Administrator, New Delhi, Issue 1, 2001. Disponível em: $<$ http://www.medind.nic.in>. Acesso em: 25 jul. 2004.

CHEN, R. C.; CHUNG, H. C. Cause-effect analysis for target costing. Management Accounting Quarterly, p. 1-9, Winter 2002.

CHINEN; C. A. K. Contribuição à gestão financeira hospitalar no Brasil. 1987. 168p. Tese (Doutorado em Controladoria e Contabilidade) - Faculdade de Economia, Administração e Contabilidade da Universidade de São Paulo, São Paulo.

CHING, Y. H. Manual de custos de instituições de saúde: sistemas tradicionais de custos e sistema de custeio baseado em atividades (ABC). São Paulo: Atlas, 2001.

ELLRAM, L. M. Purchasing and supply management's participation in the target costing process. The Journal of Supply Chain Management, $\mathrm{v}$. 36, n. 2, p. 39-51, Spring 2000.

LAKATOS, E.; MARCONI, M. A. Metodologia do trabalho cientificio. 2. ed. São Paulo: Atlas, 1989.

LOVELOCK, C.; WRIGTH, L. Serviços: marketing e gestão. São Paulo: Saraiva, 2002.

MANO, C. A. Expansão do Albert Einstein. Exame: São Paulo, Abril. 823. ed. p. 66-68, 04.08.2004.

MARTINS, E. Contabilidade de custos. 9. ed: São Paulo: Atlas, 2003.

MARTINS, G. A. Manual para elaboração de monografias e dissertações. 2. ed. São Paulo: Atlas, 2000

MONDEN, Y. Sistemas de redução de custos custo-alvo e custo Kaisen. Porto Alegre: Bookman, 1999. 
ROBINSON, F. A practical guide to target costing: processes and techniques. London: Kogan Page, 1999.

SAKURAI, M. Target costing and how to use it. Journal of Cost Management, Boston, v. 3, n. 2, p. 39-50, Summer 1989.

SAMADDAR, D. P. et al. Value engineering in tata main hospital ICU. Health Administrator, New Delhi, Issue 1, 2001. Disponível em: $<$ http://www.medind.nic.in>. Acesso em: 25 jul. 2004.

SHANK, J. K.; FISHER, J. Case study: target costing as a strategic tool. Sloan Management Review, Cambridge, v. 41, n. 1, p. 73-82, Fall 1999. SWENSON, D. et al. Best practices in target costing. Management Accounting Quarterly, v. 4, n. 2, p. 12-17, Winter 2003.

YIN, R. K. Estudo de caso: planejamento e método. Porto Alegre: Bookman, 2001.

\section{NOTA - Endereço dos autores}

Universidade Estadual de Maringá Departamento de Ciências Contábeis Av. Colombo, 5790 - Bloco C23 Maringá - PR $87020-900$
Universidade de São Paulo

Faculdade de Economia, Administração e Contabilidade

Departamento de Contabilidade e Átuária

Av. Prof. Luciano Gualberto, 908 - prédio 3 - Cidade Universitária

São Paulo - SP

05508-900 